\title{
Exploring Determinants of Urban Motorcycle Accident Severity: The Case of Barcelona
}

\author{
Daniel Albalate \& Laura Fernández-Villadangos \\ University of Barcelona* \\ (ppre-IREA)
}

\begin{abstract}
Public authorities and road users alike are increasingly concerned by recent trends in road safety outcomes in Barcelona, which is the European city with the highest number of registered Powered Two-Wheel (PTW) vehicles per inhabitant. In this study we explore the determinants of motorcycle and moped accident severity in a large urban area, drawing on Barcelona's local police database (2002-2008). We apply non-parametric regression techniques to characterize PTW accidents and parametric methods to investigate the factors influencing their severity. Our results show that PTW accident victims are more vulnerable, showing greater degrees of accident severity, than other traffic victims. Speed violations and alcohol consumption provide the worst health outcomes. Demographic and environment-related risk factors, in addition to helmet use, play an important role in determining accident severity. Thus, this study furthers our understanding of the most vulnerable vehicle types, while our results have direct implications for local policy makers in their fight to reduce the severity of PTW accidents in large urban areas.
\end{abstract}

Keywords: Road Safety, Motorcycles, Mopeds, Accidents, Severity, Transportation. JEL codes: I18; K42; R41.

\footnotetext{
* Universitat de Barcelona, Departament de Política Econòmica i Estructura Econòmica Mundial, Av. Diagonal 690, Barcelona (Spain).

Daniel Albalate: Tel: +34.934021945/ e-mail: albalate@ub.edu / Fax: 34.934024573

Laura Fernández-Villadangos: +34.934039721 / e-mail: laura.fernandez@ub.edu / Fax: 34.934024573
} 


\section{Exploring Determinants of Urban Motorcycle Accident Severity: The Case of Barcelona}

\section{Introduction}

Recent road safety trends in developed countries highlight the success of safety measures being taken by the public authorities, or as a result of public concern. The European Union countries, for example, have achieved significant reductions in road accident outcomes, presenting a decreasing trend in the annual number of fatalities (Figure 1), albeit that the reduction in the number of injuries is not so clear (Table 1). All in all, these states have recorded a significant effectiveness in combating road accident severity, which has had a direct effect on health impacts and associated socioeconomic costs (Hotz et al., 2004; Mayou and Bryant, 2003; Wells et al., 2004).

Yet, this success must be treated with caution: first, because of the high number of deaths that continue to be caused by road accidents and, second, because if we disaggregate the number of road traffic deaths by vehicle type it becomes apparent that this promising outcome is not consistently supported for all vehicle types (Table 1). In fact, as in the US where annual motorcyclist fatalities more than doubled between 1997 and 2005 (Dee, 2008), motorcyclist fatalities increased by 22\% between 1996 and 2005. Moreover, as Figure 2 shows, this is the sole means of transport to record a rise in the annual number of fatalities and to show an increasing trend over the last decade (Table 1). Figure 1 shows how Powered Two-Wheeler (PTW) fatalities as a share of total annual fatalities have increased recently. But as moped-related fatalities have fallen by more than $40 \%$ for the same period, it is clear that this result is primarily attributable to motorcycle-related deaths.

\footnotetext{
$<<$ Insert Figure 1 about here $>>$

$<<$ Insert Table 1 about here $>>$

$<<$ Insert Figure 2 about here $>>$
} 
Powered Two-Wheelers (PTWs) are usually seen by the public and local authorities alike as a type of vehicle that can alleviate congestion and facilitate both mobility and parking in busy city centers. Nonetheless, PTWs are the most vulnerable of powered transport modes because of their lack of safety devices and the absence of a protecting chassis for drivers and passenger, which means motorcycle riders are more likely to suffer fatalities than car occupants (Lin and Kraus, 2008). Thus, the safety performance of PTWs is a key focal point in road safety campaigns, particularly in light of the rise in the number of motorcyclist fatalities highlighted above.

Elliott et al. (2007) stress the importance of gaining an understanding of the ways in which motorcycle crashes occur in order to reduce fatality rates. We also sustain that identifying the causes of their severity can provide important insights as well. However, the road safety literature does not provide enough research on accidents of this type, leaving initial findings somewhat inconclusive. Examples, however, of recent attempts to further research in this field include Cummings et al. (2006), Langley et al. (2000), Law et al (2008), Lin et al. (2003), Preusser et al. (1995) and Radin Umar et al. (1995, 1996) among others.

The analysis of PTW safety outcomes and their determinants is of importance both within and outside urban areas, since almost half of such fatalities occur in these zones. In particular, urban PTW fatalities accounted for $45 \%$ of total PTW fatalities in the European Union in the year 2005 according to the annual statistical report of the European Road Safety Observatory (2008). Similarly, motorcyclist fatalities are predominant in both areas representing $68 \%$ of urban PTW deaths and $76 \%$ of deaths in non-urban zones. ${ }^{1}$

This study seeks to examine the main causes of the different degrees of accident severity suffered by victims in PTW accidents - distinguishing between motorcycles and mopeds.

\footnotetext{
${ }^{1}$ Indeed, we are stressing the fact that we can account for a higher number of accidents in urban areas related to those occurred in non-urban areas, although the severity figures are just the opposite, since more deaths result in non-urban accidents.
} 
The study draws on a rich database kept by the local police in Barcelona (Spain), the second largest city in Spain. Barcelona is an interesting case to examine because it is one of the cities with the highest absolute number of registered PTWs in Europe - second only to Rome (Italy) - and the city with the most PTW vehicles per inhabitant. In addition, this city has recently recorded a rise in the ownership of motorcycles, associated with a rising number of accidents and victims (Tables 2 and 3). ${ }^{2}$

\section{$<<$ Insert tables 2 and 3 about here $>>$}

Our results show that PTW-related victims are more vulnerable in terms of their severity outcomes than other traffic accident victims. Speed violations, alcohol consumption, age and gender, as well as congestion, the number of vehicles involved, the number of road lanes, and helmet use, all play a key role in determining accident severity.

The rest of this paper is organized as follows. The next section describes the data source drawn on in order to estimate the factors that might account for motorcycle accidents and their severity, while section 3 seeks to explain the methodology adopted in conducting our analysis. We present and discuss our results in section 4 and then highlight the main conclusions and policy implications in the last two sections of the study.

\section{Data}

This study draws on the database kept by the local police in Barcelona. It is a rich source of data on the road accidents that occurred in the city of Barcelona between 2002 and $2008^{3}$, providing information about the victims, the location of the accidents, their causes, the degree of severity in terms of the number of fatalities and the number and type of vehicles

\footnotetext{
2 This increase in the number of motorcycles can be attributed, in part, to a regulatory measure enacted in 2004 in Spain that permitted car-license holders with more than three years' driving experience to ride motorbikes up to $125 \mathrm{cc}$. This measure was introduced in an attempt at improving traffic flow and at reducing the number of automobiles with just one occupant. The regulation coincided with a local council initiative promoting a new form of public transport, known as "bicing", based on a public pedal cycle renting service. The result of these modal changes in Barcelona has been an increase in the absolute number of motorcyclerelated victims, giving rise to the growing concern of public authorities and road users for PTW road safety. ${ }^{3}$ Data for 2008 are available until April of that year.
} 
involved. The dataset also provides certain details regarding victims and accidents including the results of alcohol tests administered and the state of the road at the time of the accident.

The dataset stores 175037 observations about road accident victims in the city of Barcelona, of which 57488 were victims of PTW accidents. The dataset shows that the number of PTW-accident victims maintained a steady trend at over 8500 victims between 2002 and 2004. However, an increase was recorded in 2005, which contrasted with the number of car accident victims which began to fall in that year. The increase in PTW victims continued until 2007 when there were 9652 traffic accident victims. This divergence in the trends of car- and PTW-victim numbers adds further interest to this study of PTW victims and is consistent with international trends.

Thus, from our database we can describe a preliminary profile of the average victim of a PTW accident: male, just over 31 years of age traveling on an urban road, in free-flowing traffic, involved in an accident attributable to speed violations or alcohol consumption ${ }^{4}$. It is also highly likely that the weather at the time of the accident was good and the victim was either slightly or seriously injured in the accident. Non-parametric regressions should, however, tell us more about the characterization of PTW accident victims in the city of Barcelona.

\section{Methods}

We first conducted a non-parametric analysis of the data using spline regressions so as to characterize PTW accidents in Barcelona. Secondly, we used parametric techniques to determine the associated severity of PTW accidents. To do this, we applied an ordered multinomial logistic model to estimate the determinants of accident severity risk.

\footnotetext{
${ }^{4}$ This mean profile could be influenced by the victim profile derived from road accidents happening during night hours. Indeed, drivers are more likely to use the PTW vehicles for leisure reasons than for working or other daytime aims.
} 


\subsection{Characterization of PTW accidents in Barcelona: Non-parametric analysis}

Non-parametric analysis using spline techniques is a suitable tool for examining data in which the functional form relating the variables of interest is unclear. More specifically, spline regressions provide polynomial functions by segments, where all segments are interconnected at points or knots. These knots are not necesarilly equidistant, but rather the distance separating them depends on the functional relationship being fitted in each case.

In conducting a spline regression, it is first necessary to take into account the trade-off between the main components in the polynomial: on the one hand, the closeness of the fitted function to the available real data and, on the other, the penalty function related to the curvature. Selecting the parameter that determines the trade-off between these two terms is critical in ensuring the accuracy of the fitted functional form. In this study, we selected this parameter by employing a cross-validation process. This involved starting from a set of values for the parameter and choosing the one which minimizes the prediction error out of the sample.

Spline regressions are, also, particularly useful when some of the variables involved are discrete, which is the case here with most of the variables drawn from the local police database.

It is worth to be noted that the output of spline regressions takes the graph shape, and each graph reports one inferential analysis between two variables of interest controlling by some characteristics like the gender of the victim, the kind of PTW vehicle driven or the type of road in which the accident took place.

Finally, the non-parametric regressions undertaken here used the age of victims variable so as to have a continuous variable in the analysis. The aim of using the age variable is twofold: firstly, because including the age adds explanatory power to the regressions, 
enabling us to establish behavior patterns by age bands and, secondly, the continuous nature of the age variable helps, at times quite crucially, to interpret the results obtained from the splines more accurately.

All regressions are disagregated by PTW-vehicle type in order to identify differences in the characteristics of motorcycle and moped accidents. These we analyze in terms of age, the influence of particular patterns of behavior by gender in terms of the causes of the accident and, finally, the role played by the road (urban or interurban) on which the accident took place.

The results derived from this preliminary analysis provide the framework for the next step which is an investigation of the determinants of PTW-accident severity.

\subsection{Risk factors explaining PTW-accident severity}

Degrees of accident severity are included in the local police database for Barcelona, thereby enabling us to construct a categorical variable that captures different ranks of severity. Once an ordered dependent variable has been obtained, we can then use it to estimate the determinants of differences in the degree of accident severity. Thus, the endogenous variable Severity contains three increasing degrees of severity according to police reports following the accident: non-severe, severe and fatal. We can then apply an ordered multinomial logistic regression using the following groups of potential determinants as explanatory variables of accident severity: ${ }^{5}$

\subsubsection{Demographic risk factors}

The local police database includes data on the age and gender of each victim. We proceeded to categorize the continuous age variable using different age groups to identify

\footnotetext{
${ }^{5}$ The ordered logit model is based on a continuous latent variable specified as $\mathrm{yi}^{*}=\beta$ ' $\mathrm{xi}+\varepsilon$, where $\mathrm{yi}{ }^{*}$ measures the injury severity of the victim. This $y_{i}^{*}$ is unobserved, and the model assumes that $y_{i}$ is the observed discrete variable that reflects the different severity levels for victim i. The relationship between the latent variable and the discrete observed one will be obtained from the model according to $\mathrm{y}_{\mathrm{i}}=1$ if $\infty \leq \mathrm{y}_{\mathrm{i}}{ }^{*} \leq \mu_{1} ; \mathrm{yi}=2$ if $\mu_{1} \leq \mathrm{y}_{\mathrm{i}} *<\mu_{2}, \mathrm{yi}=3$ if $\mu_{2} \leq \mathrm{y}_{\mathrm{i}} *<\mu_{3}$, and so on. Those $\mu_{\mathrm{i}}$. are the thresholds where the discrete observed responses are defined and they must be estimated. Parameter estimates are obtained by maximum likelihood. See Ayuso and Santolino (2007) for a deep and clear description of the ordered logit model and Liao (1994) to get an overview on how to interpret probability models.
} 
heterogeneous severity patterns. The base category was the group of youngest victims i.e., those under the age of 20 . Therefore, the odds ratios associated with all the other age groups are compared with this youngest group. In addition, we identified the gender of the victims using the variable Male, as it is commonly assumed and regularly found that gender affects road driving behavior (Turner and McClure, 2003). Thus, it is reasonable to expect different severity outcomes.

\subsubsection{Environment-related risk factors}

The severity of an accident can be determined by several environmental elements that favor low health impacts or, on the contrary, aggravate the risk of suffering a severe accident. On the one hand, we control by traffic density. The studies undertaken by Noland et al (2008) and Noland and Quddus (2004 and 2005) report the positive impact of congestion on road safety outcomes. In their analysis of London's traffic, they conclude that their results are inconclusive and suspect that the role of congestion as a mitigator of crash severity is less likely to be present in urban conditions than it is on motorways. Here, therefore, we include congestion to test the hypothesis that it reduces severity owing to lower vehicle speeds and less space in a large city like Barcelona.

A further factor we consider is the number of vehicles involved in the accident. We expect to find different severity patterns resulting from accidents involving one vehicle and those involving two or more. We also take into consideration the number of traffic lanes at the site of the accident, as we expect road width and lane choice to be significant factors of accident outcomes. A related factor that we include here are the city's ring roads, which serve as interurban or access roads. We expect urban and interurban mobility to differ and, for this reason, we also expect road accident severity to be different.

Finally, we include a weather-related variable to capture the effect of rain on accident severity. Bad weather conditions are expected to affect road safety, but different transport modal choice is usually recognized, especially by two-wheel users when it rains. This 
counter-effect, as well as the fact that speed is reduced because of wet conditions, can offset the expected severity damage.

\subsubsection{Primary causes of accidents}

Following a traffic accident, the local police unit establishes the main cause of the crash. The most common causes included in the database are those related to alcohol consumption, speed violations and poor road surfaces. The first two have been well defined and are widely discussed in the literature (see, Albalate, 2008; Dee and Sela, 2003; Kasantikul et al., 2005). Therefore, we included these three categories and then compared them with other potential causes.

\subsubsection{Safety devices and regulatory measures}

Most drivers can rely on various safety devices to reduce the effects of an accident helmets in the case of motorcycle and moped riders and seat-belts for the users of nonPTW vehicles. And, as we would expect to find lower degrees of accident severity in victims using these devices (Cohen and Einav, 2003; Dee, 2008; Houston and Richardson, 2008; Loeb, 2001), we introduce a binary variable identifying the use of such a device by the victim. Two studies have, in fact, confirmed the effectiveness of the implementation of the compulsory use of helmets in Barcelona (Ballart and Riba, 1995; Ferrando et al., 2000).

Finally, to reflect the change in the regulation allowing car drivers with more than 3 years' experience to use a certain class of motorcycle up to $125 \mathrm{cc}$, we introduced a dummy variable with a value of 1 to indicate the years following this change and 0 for the years preceding it. This variable was labeled Regulation_2004 and aimed to capture the effect of the increase in the number of motorcycles in the city of Barcelona. As Segui-Gómez and Lopez-Valdes (2007) point out, it is no surprise that the number of fatal motorcycle-related crashes increased between 2003 and 2005 in Barcelona, despite the more widespread use of helmets. Further, Paulozzi (2005) has described a positive relationship between motorcycle 
sales and mortality rates in the US. By contrast, Magazzù et al. (2006) stress that drivers owning a motorcycle license tend to be less responsible for motorcycle-car crashes than drivers who do not hold one. However, the regulation was introduced in Spain as a means of alleviating urban traffic congestion without considering any potentially negative impact on road safety.

\subsubsection{Vehicle vulnerability}

One of the assumptions underlying this study is that PTW vehicles are more vulnerable in accidents than other vehicles. This point has been argued and demonstrated by several previous studies. To show that victims riding this type of vehicle present worse severity outcomes than other road accident victims, we include two variables identifying victims as having been involved in either motorcycle or moped accidents. The odds ratio of these explanatory variables then have to be compared to those obtained for all other vehicles in the estimation of the whole sample of victims.

\section{Results}

Here, we present the main characteristics of PTW-accident victims so as to gain an insight into the types of accident in which they tend to be involved. Then, we present our main findings from the analyses conducted in which we examine the degree of severity of these accidents.

\subsection{Profile of PTW accidents}

Our presentation of the results begins by examining the relationship between the age of the victims and the causes of their accidents, distinguishing between motorcycles and mopeds (see Figure 3). In the case of motorcycles, it is evident that the main cause of accidents for all victims under the age of 60 is a violation of the speed limit. At older ages, however, other factors seem to have contributed to the accidents. A certain amount of caution, though, is required in interpreting this last result, since the number of observations 
is markedly lower for this age group, affecting to some degree the accuracy of the nonparametric estimation. In the case of mopeds, alcohol consumption was found to be the main contributory factor in accidents involving riders between the ages of 35 and 55.

The second relationship analyzed here was that which existed between the causes of the accident and the gender of the victims, taking into consideration once again the age of the victim and the PTW type (motorcycle or moped). Figure 4a indicates a range of different causes of motorcycle accidents depending on the gender of the victim. For male users, the main cause of accidents, across most age groups, was a speed violation. However, there was a wider range of causes of accidents involving female riders, including alcohol consumption, speed violations and bad road conditions. Thus, our results point to a more complex behavior in the case of female victims of motorcycle accidents.

In the case of mopeds, Figure $4 \mathrm{~b}$ again reveals differences in behavior according to gender. For men, we found the same relationship as that observed between age and the causes of motorcycles accidents, while the behavior of women was more complex. However, alcohol consumption was not a particularly relevant factor. By contrast, speed violations were significant for young female drivers, while poor road conditions were significant for older female drivers. The consumption of drugs was also a factor in women aged around 50 .

The third relationship we examine is that between the cause of accident and the road type on which it occurred, distinguishing between urban and interurban roads (see Figures $5 \mathrm{a}$ and $5 \mathrm{~b}$, respectively). Figure $5 \mathrm{a}$ shows that motorcycles accidents on urban roads are mainly caused by speed violations. The same is true on interurban roads, although here road conditions also play an important role. Finally, Figure 5b shows that moped accidents involving young riders on urban roads are caused mainly by speed violations, those involving middle-aged victims by alcohol consumption, and once more, those involving older victims are caused by excess speed. However, in the case of accidents that occurred 
on interurban roads, the main cause was speed violations. Yet, here again, given the small number of observations for victims over 60 years of age caution should be observed when interpreting the significant fall in the functional relationship for this result.

Following this preliminary analysis, which has served to characterize the profile of PTWaccidents in the city of Barcelona, we now turn to examine the determinants of their severity.

\subsection{Determinants of PTW-accident severity}

By applying an ordered multinomial logistic regression model to the local police database we are able to observe that for all victims involved in motorcycle or moped accidents the risk of suffering an accident with a high degree of severity is statistically significant and greater than that of victims involved in other types of accident (Table 4, specification 1). Thus, the risk of a motorcycle accident victim suffering a severe accident was 2.3 times greater than the risk associated with other vehicle types, and the risk for a moped accident victim was 1.83 times higher, according to the respective odds ratio and the 95\% confidence intervals. Therefore, we can confirm that PTW users are more vulnerable than other road users to suffering severe accidents. These differences in accident severity stress the importance of analyzing the particular factors that might have an impact on the degree of severity of PTW accidents.

\section{$<<$ Insert table 4 about here $>>$}

Having estimated the main determinants of accident severity for all vehicle types, we replicated the same estimation using separate data for PTW victims in order to identify heterogeneous severity patterns with the rest of vehicles. Specification (2) replicates the estimation for motorcycle victims and specification (3) does the same for moped victims. The rest of vehicle-related victims are also treated separately in specification (4).

The main risk factor involved in severe accidents was found to be speed violations. This result was confirmed by both aggregate and restricted estimations based on different 
subsets of vehicle-type victims. Thus, victims of accidents attributable to speed violations seem more likely to suffer a severe outcome (almost five times more probable than for any other accident cause when estimates are conducted for the whole sample of victims). In the case of motorcycle-related victims (specification 2), this odds ratio is even greater (6.29). Alcohol consumption was also found to be statistically significant at the $95 \%$ confidence interval, increasing the severity risk in PTW accident victims (specifications 2 and 3), while poor road surfaces had the opposite effect, suggesting that these accidents are not as dangerous as those attributable to excess speed or alcohol.

The demographic variables also provide interesting results. On the one hand, the coefficient associated with the oldest age group was statistically significant, indicating that these victims are more likely to suffer more severe accidents than their younger counterparts, presumably owing to a greater vulnerability because of their age. Although this result was confirmed for any type of vehicle-related estimation, it was more important in the case of non-PTW victims. On the other hand, in the case of gender, males are associated with a higher severity risk (1.38), while no significant differences were found across disaggregated estimates.

Environment-related risk factors also seem to play an important role in the determination of accident severity. As shown in Table 4, congestion is associated with lower degrees of accident severity in Barcelona. This result is particularly important in the case of motorcycles and in that of non-PTW-accident victims, while for mopeds no statistical significance was reported. Similarly, interesting results can be drawn from the number of vehicles involved in the accident. Accidents involving more than one vehicle are associated with lower degrees of severity compared to those in which just one vehicle is involved, with the exception of moped-related victims. Similarly, suffering an accident on a road with more than two lanes favors safety outcomes by reducing the severity risk in all vehicle-type 
victims. By contrast, rainy weather does not seem to increase the degree of severity for the victims.

The impact of ring roads as a location factor of traffic accidents emerges as a key element for justifying disaggregated estimates by vehicle type. According to specification (1), which takes into account the whole sample of victims, these interurban routes do not have any consequences in terms of accident severity. However, when our models are applied to disaggregated groups of victims it becomes apparent that PTW accident victims tend to suffer more severe accidents on this type of road than on urban routes, while non-PTW accident victims seem to suffer less severe accidents on ring roads.

The last two variables to be tested were those related to safety devices and the regulatory license change. Both coefficients were statistically significant for the determination of motorcycle and non-PTW accident victims, while no statistical significance was found in the case of mopeds. Victims wearing a helmet or seat-belt suffered less severe accidents than those suffered by victims without these devices in the first two cases, while no differences were found for moped-related victims probably due to the high percentage of usage. Therefore, the promotion of their use seems effective, albeit that it is less important in the case of mopeds in Barcelona. However, the odds ratio associated with the regulatory variable suggests that the new measure did not increase aggregate victim severity in the city of Barcelona, although it was probably responsible for a higher number of PTW collisions. In fact, we found that accidents occurring after its implementation tended to be less severe for all types of vehicle-related victim.

\section{Conclusions}

This study has sought to further our understanding of the factors accounting for the degree of severity of road accidents by drawing on data from Barcelona, the city with the highest number of registered PTW vehicles per capita in Europe. Our analysis has been conducted in two stages: first, we characterized the PTW accidents in the city of Barcelona 
using non-parametric regression techniques and, second, we estimated the factors that account for accident severity. In both stages we employed the Barcelona local police database of registered accidents.

Our analysis confirms that victims of PTW-related accidents tend to suffer more severe injuries than other road traffic victims, highlighting the need to examine the determinants of these specific accidents and the characteristics of those involved.

Victims of motorcycle accidents were found to present higher degrees of accident severity when they presented the following characteristics: male, over 60 years of age, involved in an accident on a city ring road where the cause was a speed violation or attributable to alcohol consumption. By contrast, the degree of severity tended to fall with increasing congestion, in accidents involving more than one vehicle, on roads with more than two lanes and where the accident was attributable to deterioration in the road surface. Wearing a helmet was also found to be a severity-reducing factor, while the regulatory changes introduced to promote the use of PTWs did not affect the degree of severity recorded for accidents involving these vehicles.

Victims of moped accidents presented a number of differences, however. These concerned accidents in congested traffic, those involving more than one vehicle, and the effectiveness of helmets. The associated coefficients of all these covariates, while significant for motorcycles, were not statistically significant for mopeds. The same was true of alcohol consumption as the main cause of the accident, which lost its statistical significance in the case of mopeds.

Thus, our results show that victims of PTW-related accidents are more vulnerable in terms of severity than other road accident victims. Further, we are able to provide interesting insights into the role of environment-related risk factors, demographic characteristics and helmet use in severity determination. Our study highlights the fact that PTW accidents are typified by a certain set of characteristics and that the determinants of 
accident severity vary according to the type of vehicle involved. As such, our research has enabled us to further our understanding of the most vulnerable type of vehicles on the road today and this has obvious implications for local policy makers as they fight to reduce the number and severity of PTW road accidents. These policy implications are summarized below.

\section{Policy Implications}

This study offers a number of insights into PTW-accident profiles and as such has interesting implications for policy makers seeking to implement measures that might increase road safety for these particular users. Thus, although this study is based on local data from Barcelona, our results are indeed applicable to large urban areas.

First, our study has shown that in large urban areas PTW accident victims are more likely to suffer severe injuries than non-PTW accident victims. Hence the need for local authorities to pay particular attention to PTWs when designing road safety programs and for local police units to consider the specific problems of these vehicles when preparing their intervention and enforcement plans. Our findings indicate that accidents involving PTWs are characterized by a different set of characteristics from those present in accidents involving other types of vehicle. Moreover, the role played by certain determinants of severity seems to differ according to the type of vehicle. Consequently, authorities need to adopt a specific road safety policy adapted to the needs of PTWs, and this policy may be different from that typically implemented for other vehicles.

Further, our study stresses the importance of speed violations and the associated severity of the accident, to the extent that victims of accidents attributable to drivers having violated the speed limit present the highest degree of accident severity. Thus, restricting speed limits is essential, though perhaps not in itself sufficient. Policy makers must to persevere in their organization of speed control campaigns, while seeking to ensure that 
high-risk drivers respect highway regulations. Similar arguments can be made in the cases of alcohol consumption and the wearing of protective helmets.

Our study also reports evidence of the fact that less traffic congestion - an environmentrelated factor - can increase accident severity. This suggests that measures designed to fight congestion, such as road-charging schemes, should also take into consideration their impact on the undesired outcomes of road accidents when they are under review. It is critical that an undesired result is not permitted at the expense of the benefits gained from a cut in congestion costs.

Finally, our study highlights the need for road safety awareness campaigns to target male drivers. Likewise, particular attention should be given to the older age groups as they are the ones most likely to suffer the most severe accidents. It would therefore appear logical to design special safety devices for road users with these demographic characteristics and to restrict the conditions of PTW use among older drivers.

\section{Acknowledgements}

This research has been funded by the RACC Foundation (Spain) and by the Spanish Commission of Science and Technology (SEJ2006-04985). We are grateful for comments and suggestions received from Alejandro Estruch and Mercedes Ayuso.

\section{References}

Albalate, D., 2008. Lowering blood alcohol content levels to save lives: The European experience. Journal of Policy Analysis and Management 27(1), 20-39.

Ayuso, M. and Santolino, M., 2007. Predicting automobile claims bodily injury severity with sequential ordered logit models. Insurance Mathematics and Economics 41, 71-83.

Ballart, X. and Riba, C., 1995. Impact of legislation requiring moped and motorbike riders to wear helmets. Evaluation and Program Plannin 18, 311-320. 
Cohen, A. and Einav, L., 2003. The effects of mandatory seat belt laws on driving behavior and traffic fatalities. The Review of Economics and Statistics 85(4), 828-843. Cummings, P., Rivara, F.P., Olson, C.M. and Smith, K.M., 2006. Changes in traffic crash mortality rates attributed to use of alcohol, or lack of a seat belt, air bag, motorcycle helmet, or bicycle helmet, Unitete States, 1982-2001. Injury Prevention 12, 148-154.

Dee, T.S., 1998. Reconsidering the Effects of Seat Belt Laws and Their Enforcement Status. Accident Analysis and Prevention 30(1), 1-10.

Dee, T.S., 2008. Motorcycle helmets and traffic safety. Journal of Health Economics, doi:10.1016/jhealeco.2008.12.002

Dee, T. S. and Sela, R,J., 2003. The fatality effects of highway speed limits by gender and age. Economic letters 79, 401-408.

Elliot, M.A., Baughan, C.J. and Sexton, B.F., 2007. Errors and violations in relation to motorcyclists' crash risk. Accident analysis and prevention 39, 191-499.

European Road Safety Observatory, 2008. Annual Statistical Report 2007, SafetyNet, Directorate-General Energy and Transportation (European Commission).

Ferrando, J., Plasencia, A., Orós, M., Borrell, C. and Krauss, J.F., 2000. Impact of a helmet law on two wheel motor vehicle crash mortality in a southern European urban area. Injury Prevention 6, 184-188.

Houston, D.J. and Richardson, L.E., 2008. Motorcyclist fatality rates and mandatory helmet-use laws. Accident Analysis and Prevention 40, 200-208.

Hotz, G.A., Cohn, S.M., Mishkin, D., Castelblanco, A., Li, P. Popkin, C., Duncan, R. 2004. Outcome of motorcycle riders at one year post. Traffic Injury Prevention 5, 87-89.

Kasantikul, V., Ouellet, J.V., Smith, T. , Sirathranont, J. and Panichabhongse, V., 2005. The role of alcohol in Thailand motorcycle crashes. Accident Analysis and Prevention 37, 257-366. 
Langley, J., Mullin, B., Jackson, R. and Norton, R. 2000. Motorcycle engine size and risk of moderate to fatal injury from a motorcycle crash. Accident Analysis and Prevention 32, 659-663.

Law, T.H., Noland, R. and Evans, A.W., 2008. Factors associated with the relationship between motorcycle deaths and economic growth. Accident Analysis and Prevention, doi: 10.1016/j.aap.2008.11.005

Liao, T., 1994. Interpreting probability models: logit, provit and other generalized linear models. Sage University Paper Series on Quantitative applications in the Social Science 07101. Thousand Oaks, CA, Sage, California.

Lin, M. Chang, S., Pai, L., Keyl, P.M., 2003. A longitudinal study of risk factors for motorcycle crashes among junior college students in Taiwan. Accident analysis and prevention 35 (2), 243-252.

Lin, M. and Kraus, J.F., 2008. Methodological issues in motorcycle injury epidemiology. Accident Analysis and Prevention 40 (5), 1663-1660.

Loeb, P.D., 2001. The effectiveness of seat belt legislation in reducing driving involved injury rates in Maryland. Transportation Research Part E 37, 297-310.

Magazzù, D., Comelli, M. and Mariononi, A., 2006. Are car drivers holding a motorcycle licence less responsible for motorcycle-car crash occurrence? A non-parametric approach. Accident Analysis and Prevention 38, 365-370.

Mayou, R. and Bryant, B., 2003. Consequences of road traffic accidents for different types of road user. Injury 34, 197-202.

Noland, R. and Quddus, M., 2004. A spatially disaggregate analysis of road casualties in England. Accident Analysis and Prevention 36 (6), 973-984.

Noland, R. and Quddus, M., 2005. Congestion and safety: a spatial analysis of London. Transportation Research. Part A 39, 737-754. 
Noland, R. and Quddus, M. and Ochieng, 2008. The effect of the London congestion charge on road casualties: an intervention analysis, Transportation 35 (1), 73-91.

Paulozzi, L.J., 2005. The role of sales of new motorcycles in a recent increase in motorcycle mortality rates. Journal of Safety Research 36, 361-364.

Preusser, D.F., Williams, A.F., Ulmer, R.G., 1995. Analysis of fatal motorcycle crashes: crash typing. Accident analysis and prevention 27 (6), 845-851.

Radin Umar, R.S., Mackay, G.M., Hills, B.L., 1995. Preliminary analysis of motorcycle accidents: Short-term impacts of the running headlights campaign and regulation. Journal of Traffic Medicine 23 (1), 17-28.

Radin Umar, R.S., Mackay, G.M. and Hills, B.L., 1996. Modelling of Conspicuity-Related Motorcycle Accidents in Seremban and Shah Alam, Malaysia. Accident Analysis and Prevention 28 (3), 325-32

Segui-Gómez, M. and Lopez-Valdes, F.J., 2007. Recognizing the importance of injury in other policy forums: the case of motorcycle licensing policy in Spain. Injury prevention 13, 429-430.

Turner, C. and McClure, R., 2003. Age and gender differences in risk-taking behaviour as an explanation for high incidence of motor vehicle crashes as a driver in young males. International Journal of Injury Control and Safety Promotion 10 (3), 123-130.

Wells, S., Mullin, B., Norton, R., Langley, J., Connor, J., Lay-Yee, R., Jackson, R., 2004. Motorcycle rider conspicuity and crash related injury: case-control study. BMJ 328, 857. 


\section{TABLES}

Table 1. Road safety trends by type of vehicle in the EU14, 1996-2005.

\begin{tabular}{|c|c|c|c|c|c|c|c|c|c|c|c|}
\hline & 1996 & 1997 & 1998 & 1999 & 2000 & 2001 & 2002 & 2003 & 2004 & 2005 & $\begin{array}{l}\% \text { Change } \\
1996-2005\end{array}$ \\
\hline Total Injury Accidents & 885843 & 893543 & 918118 & 938868 & 933426 & 913814 & 898347 & 856574 & 823542 & 875613 & $-1 \%$ \\
\hline Total Fatalities & 34868 & 34763 & 34552 & 34151 & 33486 & 32882 & 31758 & 29243 & 26919 & 26060 & $-25 \%$ \\
\hline Pedal cycle & 1775 & 1809 & 1647 & 1647 & 1507 & 1457 & 1358 & 1291 & 1210 & 1215 & $-31 \%$ \\
\hline Cars and Taxis ${ }^{1}$ & 27677 & 27648 & 27714 & 27103 & 26587 & 25979 & 25323 & 22804 & 20746 & 20051 & $-27 \%$ \\
\hline Lorries and heavy goods $>3.5 \mathrm{t}^{1}$ & 4585 & 4544 & 4521 & 4671 & 4503 & 4169 & 4025 & 3686 & 3417 & 3350 & $-27 \%$ \\
\hline Lorries and heavy goods $<3.5 \mathrm{t}^{1}$ & 3503 & 3236 & 2973 & 3248 & 3035 & 3157 & 2988 & 2809 & 2464 & 2398 & $-28 \%$ \\
\hline Bus and Coaches & 889 & 1017 & 1007 & 905 & 862 & 883 & 748 & 773 & 689 & 633 & $-28 \%$ \\
\hline PTW & 5769 & 5981 & 5846 & 5894 & 5832 & 5887 & 5653 & 5651 & 5484 & 5496 & $-5 \%$ \\
\hline Moped & 2455 & 2481 & 2331 & 2267 & 2093 & 1931 & 1680 & 1730 & 1539 & 1449 & $-41 \%$ \\
\hline Motorcycle & 3314 & 3500 & 3515 & 3627 & 3739 & 3956 & 3973 & 3921 & 3945 & 4047 & $22 \%$ \\
\hline$\%$ PTW Fatalities & 16.5 & 17.2 & 16.9 & 17.3 & 17.4 & 17.9 & 17.8 & 19.3 & 20.4 & 21.1 & $28 \%$ \\
\hline Motorcycle & 9.5 & 10 & 10.1 & 10.6 & 11.1 & 12 & 12.5 & 13.3 & 14.6 & 15.5 & $63 \%$ \\
\hline Moped & 7 & 7.1 & 6.7 & 6.6 & 6.3 & 5.9 & 5.3 & 5.9 & 5.7 & 5.6 & $-20 \%$ \\
\hline
\end{tabular}

Source: European Road Safety Observatory (2008), CARE database.

1. The European Road Safety (2008) provides numbers of fatalities in cars and taxis plus all other vehicle fatalities. This means that car-related and lorry-related fatalities are over-estimated. 
Table 2. Registered vehicles in the city of Barcelona 2003-2007.

\begin{tabular}{|r|c|c|c|c|c|c|}
\hline $\begin{array}{c}\text { Registered vehicles in } \\
\text { Barcelona }\end{array}$ & $\mathbf{2 0 0 3}$ & $\mathbf{2 0 0 4}$ & $\mathbf{2 0 0 5}$ & $\mathbf{2 0 0 6}$ & $\mathbf{2 0 0 7}$ & $\begin{array}{c}\text { Change } \\
\mathbf{2 0 0 3 - 2 0 0 7}\end{array}$ \\
\hline Total & 931258 & 942232 & 965172 & 978448 & 991151 & $6 \%$ \\
\hline Passenger cars & 603343 & 607791 & 617291 & 616814 & 617022 & $2 \%$ \\
\hline Motorcycles & 144584 & 149363 & 160392 & 173190 & 184888 & $28 \%$ \\
\hline Mopeds & 89579 & 90730 & 91650 & 93067 & 93783 & $5 \%$ \\
\hline Others & 93752 & 94348 & 95839 & 95377 & 95458 & $2 \%$ \\
\hline Bicing (Bike renting) & - & 4216 & 4552 & 7696 & 14696 & $249 \%$ \\
\hline
\end{tabular}

Source: Department of Statistics, City Council of Barcelona.

Table 3. Number of total victims and fatalities in Barcelona by mode 2002-2007

\begin{tabular}{|r|c|c|c|c|c|c|c|}
\hline & $\mathbf{2 0 0 2}$ & $\mathbf{2 0 0 3}$ & $\mathbf{2 0 0 4}$ & $\mathbf{2 0 0 5}$ & $\mathbf{2 0 0 6}$ & $\mathbf{2 0 0 7}$ & $\begin{array}{c}\text { Change } \\
\mathbf{2 0 0 3}-2007\end{array}$ \\
\hline Number of victims & & & & & & & \\
\hline PTW & 8850 & 8681 & 8532 & 9230 & 9500 & 9652 & $9 \%$ \\
\hline Rest of vehicles & 24184 & 25363 & 24505 & 25932 & 24986 & 25234 & $4 \%$ \\
\hline Pumber of Fatalities & & & & & & & \\
\hline Pest of vehicles & 42 & 27 & 28 & 28 & 39 & 33 & $50 \%$ \\
\hline
\end{tabular}

Source: Barcelona Local Police Database. 
Table 4. Logistic Regression. Estimates on the determinants of road accident severity in Barcelona by type of vehicle $2002-2008$.

\begin{tabular}{|c|c|c|c|c|c|c|c|c|}
\hline $\begin{array}{c}\text { Explanatory } \\
\text { variables }\end{array}$ & $\begin{array}{c}\text { Total } \\
\text { OR }(95 \% \mathrm{CI}) \\
\text { (1) }\end{array}$ & $\mathbf{P}>|z|$ & $\begin{array}{c}\text { Motorbikes } \\
\text { OR }(95 \% \mathrm{CI}) \\
(2)\end{array}$ & $P>|z|$ & $\begin{array}{c}\text { Mopeds } \\
\text { OR }(95 \% \mathrm{CI}) \\
\text { (3) }\end{array}$ & $P>|z|$ & $\begin{array}{c}\text { Other } \\
\text { OR }(95 \% \mathrm{CI}) \\
(4)\end{array}$ & $\mathbf{P}>|z|$ \\
\hline $\mathbf{N}$ & 64486 & & 20412 & & 17425 & & 26788 & \\
\hline \multicolumn{9}{|l|}{ Age } \\
\hline Age20-30 & $0.89(0.81-0.98)$ & 0.025 & $0.94(0.81-1.10)$ & 0.462 & $0.92(0.78-1.09)$ & 0.343 & $0.78(0.64-0.96)$ & 0.017 \\
\hline Age 30-40 & $1.08(0.78-1.48)$ & 0.628 & $1.21(0.80-1.85)$ & 0.358 & $1.43(0.60-3.43)$ & 0.420 & $0.71(0.39-1.28)$ & 0.258 \\
\hline Age 40-50 & $1.05(0.77-1.41)$ & 0.760 & $1.01(0.68-1.52)$ & 0.939 & $0.85(0.37-1.95)$ & 0.706 & $1.22(0.70-2.13)$ & 0.483 \\
\hline Age 50-60 & $1.30(0.92-1.85)$ & 0.139 & $1.26(0.79-2.03)$ & 0.331 & $1.14(0.43-2.99)$ & 0.780 & $1.65(0.87-3.15)$ & 0.128 \\
\hline Age $>60$ & $2.58(1.83-3.63)$ & 0.000 & $1.88(1.16-3.06)$ & 0.011 & $2.49(0.99-6.28)$ & 0.053 & $3.38(1.82-6.28)$ & 0.000 \\
\hline Males & $1.39(1.27-1.52)$ & 0.000 & $1.47(1.25-1.71)$ & 0.000 & $1.37(1.17-1.62)$ & 0.000 & $1.39(1.20-1.60)$ & 0.000 \\
\hline Congestion & $0.79(0.70-0.89)$ & 0.000 & $0.80(0.67-0.95)$ & 0.000 & $0.88(0.70-1.11)$ & 0.284 & $0.77(0.61-0.98)$ & 0.034 \\
\hline $\mathbf{N}^{\circ}$ Vehicles $(>1)$ & $0.58(0.52-0.63)$ & 0.000 & $0.65(0.57-0.76)$ & 0.000 & $1.01(0.85-1.19)$ & 0.897 & $0.34(0.28-0.40)$ & 0.000 \\
\hline $\mathbf{N}^{\circ}$ Lanes $(>2)$ & $0.76(0.68-0.85)$ & 0.000 & $0.72(0.60-0.88)$ & 0.000 & $0.75(0.61-0.92)$ & 0.005 & $0.81(0.67-0.97)$ & 0.025 \\
\hline \multicolumn{9}{|l|}{ Primary Causes } \\
\hline Alcohol & $1.47(1.21-1.80)$ & 0.000 & $1.66(1.17-2.35)$ & 0.000 & $1.62(1.10-2.40)$ & 0.114 & $1.31(0.96-1.79)$ & 0.085 \\
\hline Speed & $4.95(4.28-5.73)$ & 0.000 & $6.29(4.87-8.13)$ & 0.000 & $4.73(3.26-6.86)$ & 0.000 & $4.44(3.60-5.46)$ & 0.000 \\
\hline Road surface & $0.42(0.26-0.68)$ & 0.000 & $0.29(0.14-0.62)$ & 0.001 & $0.60(0.30-1.23)$ & 0.165 & $1.57(0.37-6.75)$ & 0.538 \\
\hline Rainy_Weather & $0.96(0.82-1.13)$ & 0.661 & $0.97(0.73-1.29)$ & 0.822 & $0.84(0.60-1.16)$ & 0.298 & $1.09(0.86-1.40)$ & 0.450 \\
\hline Ring_Roads & $1.09(0.92-1.28)$ & 0.291 & $1.40(1.11-1.76)$ & 0.005 & $1.77(1.24-2.52)$ & 0.002 & $0.70(0.51-0.95)$ & 0.024 \\
\hline \multicolumn{9}{|l|}{ Vehicles } \\
\hline Motorcycle & $2.30(2.08-2.54)$ & 0.000 & - & - & - & - & - & \\
\hline Moped & $1.83(1.64-2.05)$ & 0.000 & - & - & - & - & - & \\
\hline Helmet / Seat-belt & $0.63(0.55-0.72)$ & 0.000 & $0.65(0.52-0.81)$ & 0.000 & $0.86(0.69-1.07)$ & 0.191 & $0.34(0.24-0.48)$ & 0.000 \\
\hline Regulation_2004 & $0.50(0.45-0.55)$ & 0.000 & $0.50(0.43-0.59)$ & 0.000 & $0.55(0.000)$ & 0.000 & $0.47(0.40-0.55)$ & 0.000 \\
\hline Pseuro-R ${ }^{2}$ & 0.06 & - & 0.04 & - & 0.04 & - & 0.09 & - \\
\hline LR Chi2 & 696.81 & 0.000 & 234.09 & 0.000 & 422.68 & 0.000 & 758.70 & 0.000 \\
\hline /cut1 & $3.09(2.95-3.24)$ & 0.000 & $2.76(2.51-3.00)$ & 0.000 & $2.34(2.10-2.58)$ & 0.000 & $2.77(2.55-2.99)$ & 0.000 \\
\hline /cut2 & $5.43(5.25-5.62)$ & 0.000 & $5.31(4.98-5.66)$ & 0.000 & $4.67(4.39-4.96$ & 0.000 & $4.98(4.70-5.27)$ & 0.000 \\
\hline
\end{tabular}

Note: Each specification includes individual year-dummies. In parenthesis we provide the $95 \%$ confidence interval. 


\section{FIGURES}

Figure 1. Total road fatalities and the share of PTW fatalities in the EU14 (1996-2005)

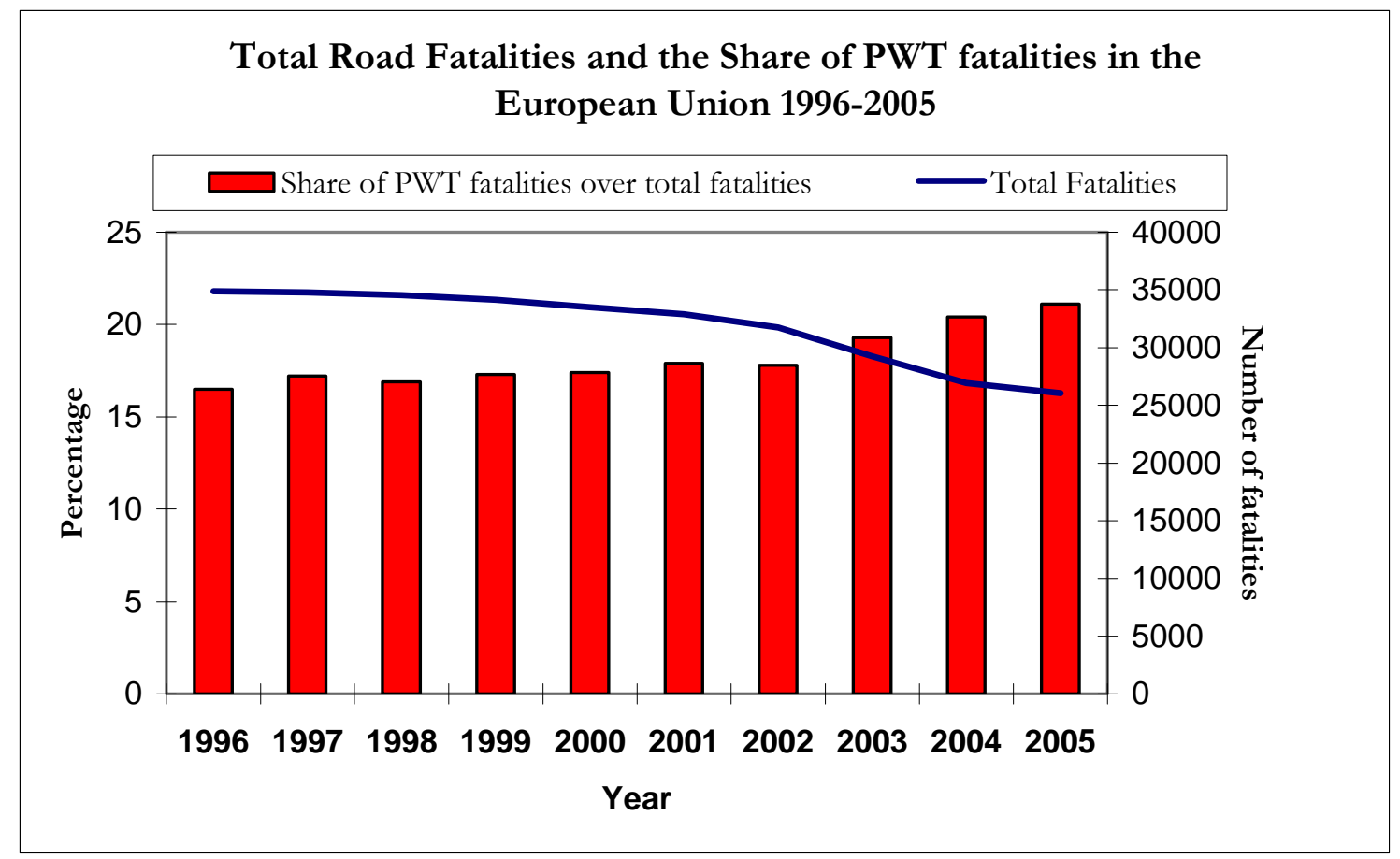

Source: European Road Safety Observatory (2008)

Figure 2. Percentage change in number of fatalities by mode of transport in the EU14 (1996-2005)

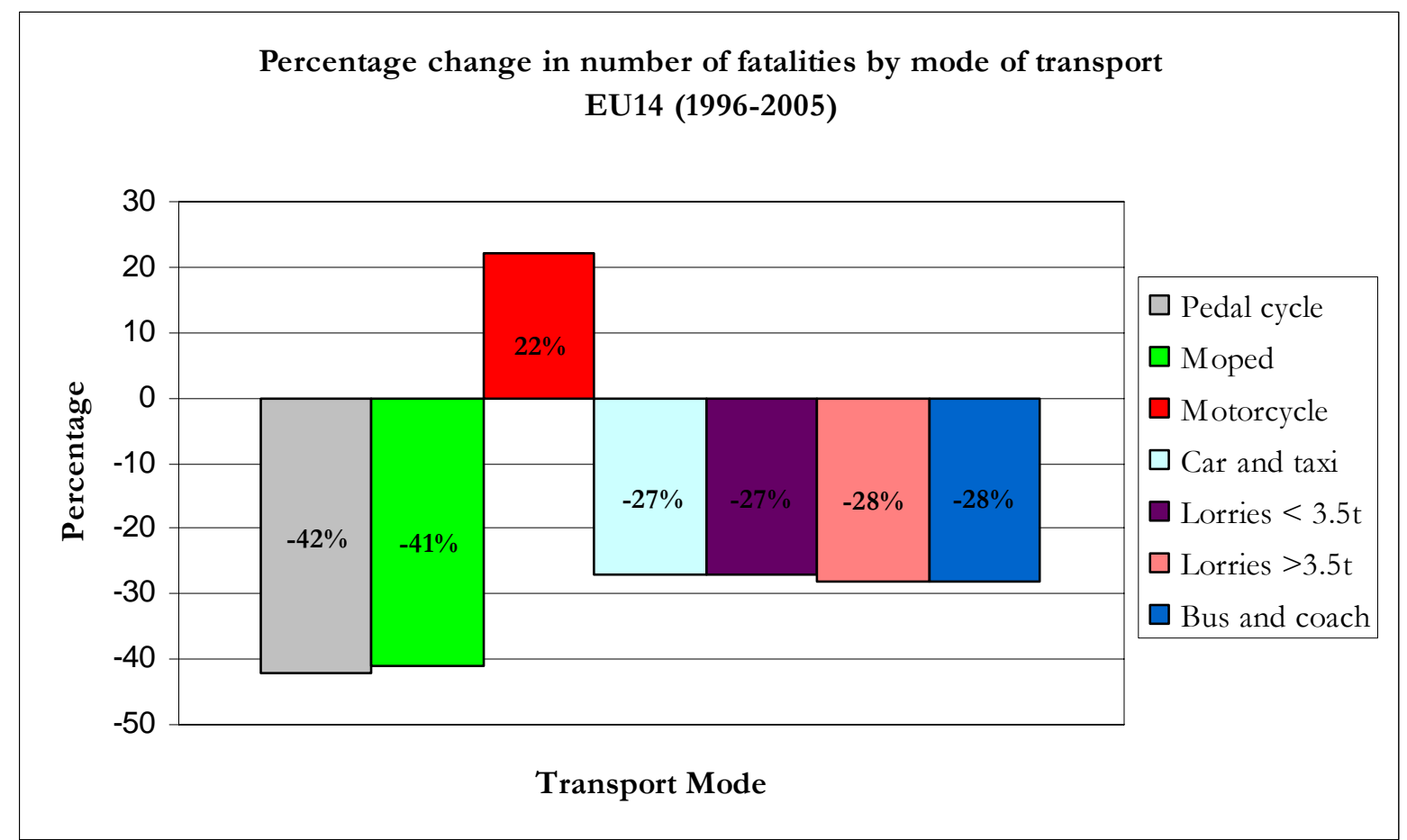

Source: European Road Safety Observatory (2008), CARE database. 
Figure 3. Relationship between age and causes of accidents.

Motorcycles

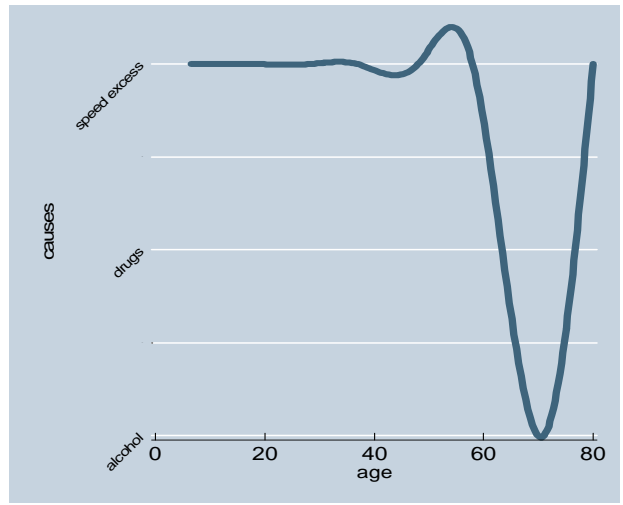

Mopeds

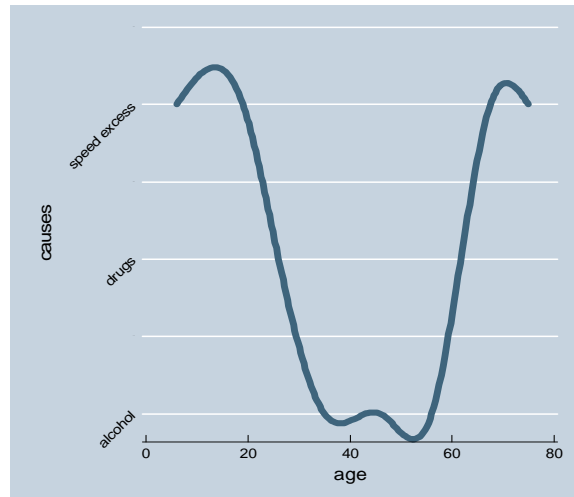

Figure 4a. Relationship between age and causes of accidents with victims by gender. Motorcycle accidents

Women

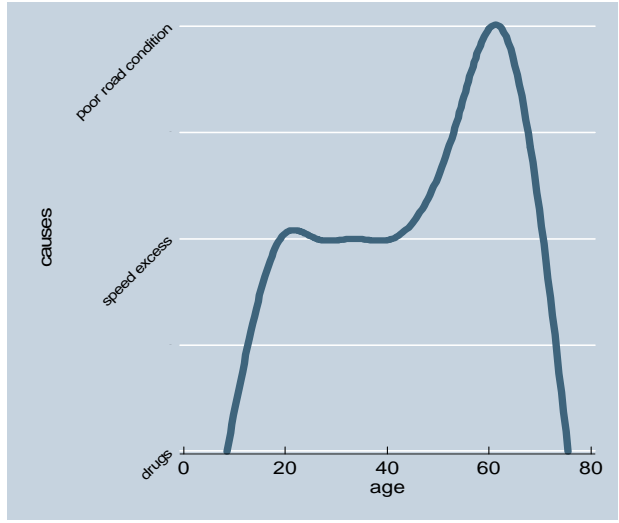

Men

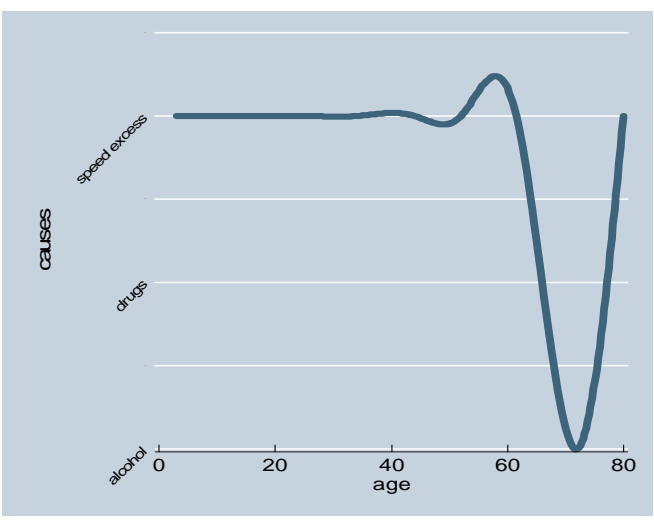

Figure 4b. Relationship between age and causes of accidents with victims by gender. Moped accidents

\section{Women}

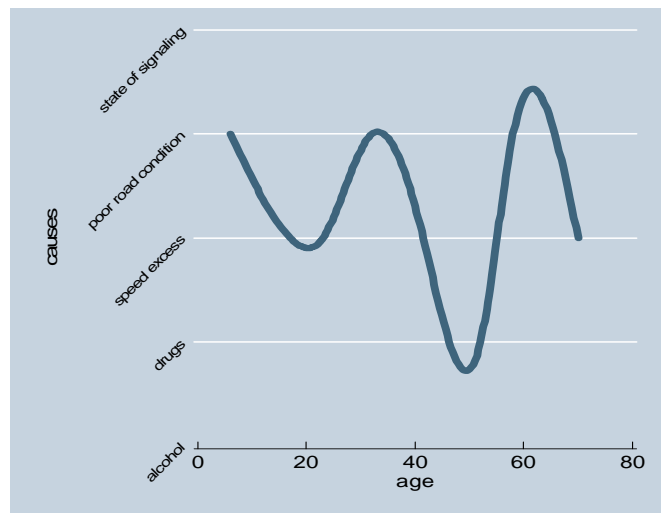

Men

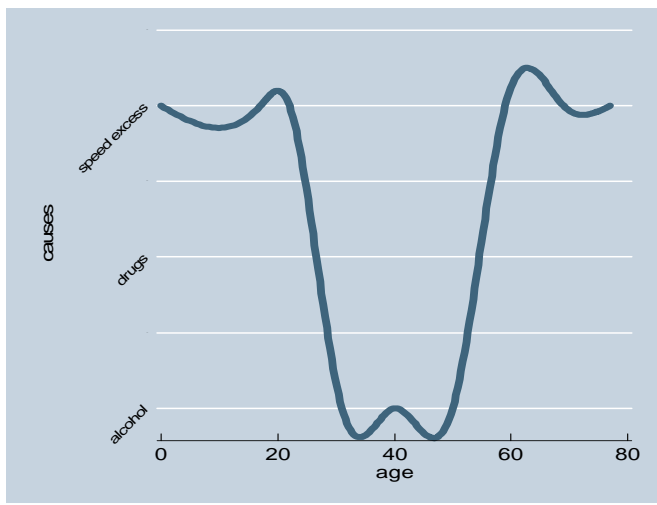


Figure 5a. Relationship between age and causes of accidents by kind of road. Motorcycle accidents

Urban

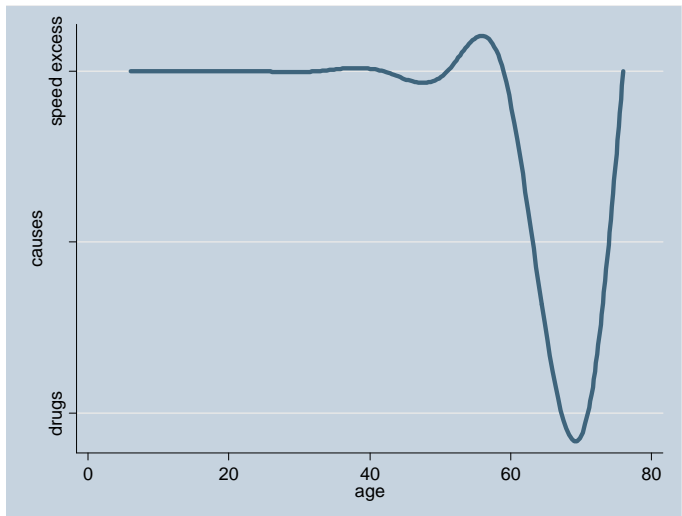

Interurban

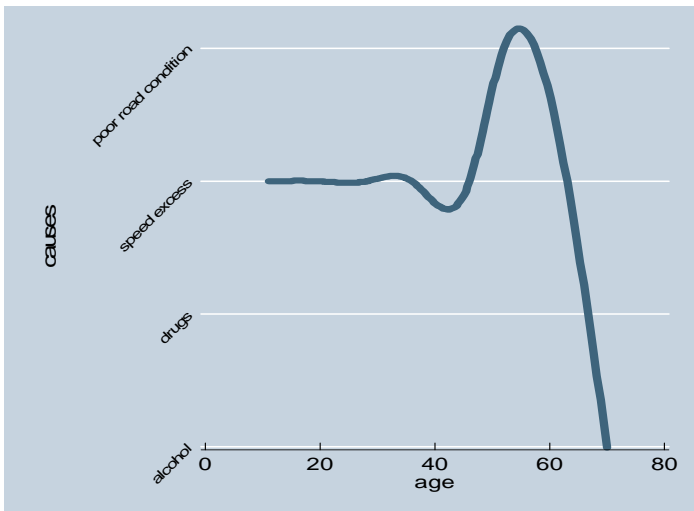

Figure 5b. Relationship between age and causes of accidents by kind of road. Moped accidents

Urban

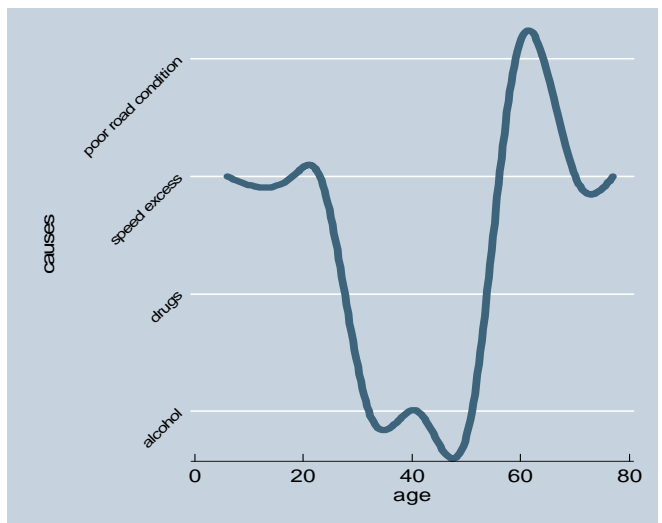

Interurban

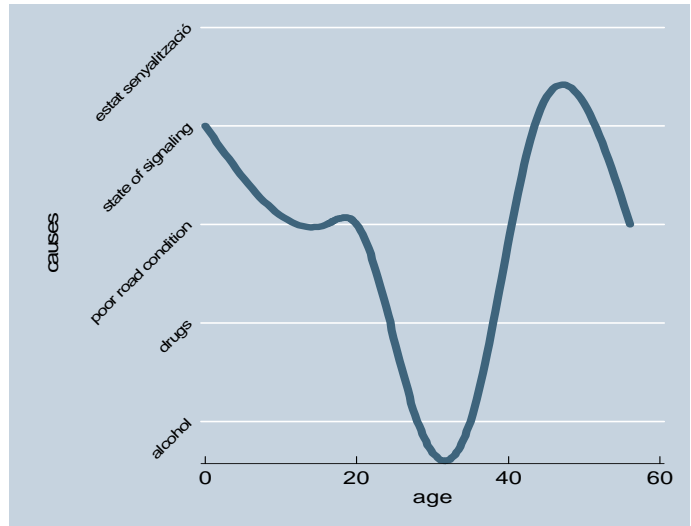

